\title{
Transcontextual Development of Motivation in Sport Injury Prevention Among Elite Athletes
}

\author{
Derwin King-Chung Chan ${ }^{1,2}$ and Martin S. Hagger ${ }^{1}$ \\ ${ }^{1}$ Curtin University; ${ }^{2}$ University of Nottingham
}

\begin{abstract}
The present study investigated the transcontextual process of motivation in sport injury prevention. We examined whether general causality orientation, perceived autonomy support from coaches (PAS), self-determined motivation (SD-Mtv), and basic need satisfaction in a sport context predicted SD-Mtv, beliefs, and adherence with respect to sport injury prevention. Elite athletes $(N=533)$ completed selfreport measures of the predictors (Week 1) and the dependent variables (Week 2). Variance-based structural equation modeling supported hypotheses: SD-Mtv in a sport context was significantly predicted by PAS and basic need satisfaction and was positively associated with SD-Mtv for sport injury prevention when controlling for general causality orientation. SD-Mtv for sport injury prevention was a significant predictor of adherence to injury-preventive behaviors and beliefs regarding safety in sport. In conclusion, the transcontextual mechanism of motivation may explain the process by which distal motivational factors in sport direct the formation of proximal motivation, beliefs, and behaviors of sport injury prevention.
\end{abstract}

Keywords: self-determination theory, hierarchical model of motivation, adherence, injured athletes, injury fatality, safety violation

Recent advances in sport medicine to enhance the effectiveness of sport injury prevention notwithstanding, sport injury has increased in the past 15-20 years, and still remains a major reason for premature retirement in elite athletes (Knowles et al., 2006). Many intervention strategies, such as safety education, physical conditioning, or neuromuscular training, and the assessment and reduction of environmental risk have been shown to work reasonably well in ameliorating sport injury incidence in the clinical settings (Bahr \& Engebretsen, 2009; Emery \& Tyreman, 2009), but their long-term benefits in the field will be largely dependent on whether the athletes and sport practitioners (e.g., coaches, physiotherapists) adopt and adhere to the necessary injury-preventive behaviors. Furthermore, research has shown that adherence

Derwin King-Chung Chan is with the School of Psychology and Speech Pathology, Curtin University, Perth, Australia, and with the Personality, Social Psychology, and Health Research Group, School of Psychology, University of Nottingham, Nottingham, UK. Martin S. Hagger is with the School of Psychology and Speech Pathology, Curtin University, Perth, Australia. 
is a serious problem when it comes to injury-preventive behavior (Chan \& Hagger, 2011; Verhagen, van Stralen, \& van Mechelen, 2010). However, in sport, research has been very limited in using psychological theories to investigate individuals' safety or injury-preventive behavior. A recent systematic review by McGlashan and Finch (2010) shows that only $11 \%$ of studies on sport injury prevention considered social or behavioral science theories. It is, therefore, imperative that researchers seek to identify the motivational and psychosocial factors that influence the uptake and adherence to injury-preventive behaviors. The purpose of the current study is to use self-determination theory (SDT; Deci \& Ryan, 1985b) and the hierarchical model of motivation (Vallerand, 2000) to explain the transcontextual motivational processes underpinning athletes' adherence and beliefs of injury prevention. The present study is original and unique because it is the first empirical investigation of sport injury-preventive behavior grounded in SDT and the hierarchical model of motivation.

\section{Autonomy Support, Basic Need Satisfaction, and Motivation}

According to self-determination theory (Deci \& Ryan, 1985b), humans have psychological needs for autonomy (feelings of volition, freedom, and choice when acting), competence (perceiving oneself to be an effective agent in the environment), and relatedness (feelings of belongingness, connection, and care from others). The extent to which these needs are satisfied will determine whether an individual functions optimally and experiences concomitant adaptive outcomes. The behaviors that are considered need satisfying are experienced as driven by autonomous motivation. Autonomous motivation is an internal drive toward engaging in a particular behavior initiated from an individuals' sense of volition, and can be classified into various forms, including intrinsic motivation (i.e., for fun, excitement and interest), integration (i.e., acting to satisfy psychological needs that are consistent with a true sense of self), and identification (i.e., acting to achieve personally valued targets). Individuals who are autonomously motivated experience a sense of personal agency and choice over their behavior and are more likely to persist with behaviors relative to individuals who are not autonomously motivated (Deci \& Ryan, 1985b). Nevertheless, behaviors may not always be need satisfying, as individuals could be driven by forces or pressures external to the sense of self. These drives from the external locus of causality are known as controlled motivation (Deci \& Ryan, 1985b). Controlled motivation may involve introjection (i.e., acting to attain contingent self-worth, or to avoid of internally felt contingencies like guilt and shame) and external regulation (i.e., acting to meet external demands, avoidance of punishment, and social pressure).

The distinction between autonomous and controlled motivation, and their proposed antecedents according to SDT, the psychological needs, provides a plausible explanatory system for the motivational processes that underlie human behavior. A substantial literature exists reporting significant links between these constructs (i.e., psychological needs satisfaction $\rightarrow$ motivation $\rightarrow$ behavior), and the adaptive nature of basic need satisfaction and self-determined motivation (i.e., the relative autonomy level of the behavioral regulation in the locus of causality based on ones' endorsement of autonomous motivation as opposed to controlled motivation; Ryan \& Connell, 1989) toward behavioral outcomes in sport, exercise, and 
health domains (Fortier, Sweet, O’Sullivan, \& Williams, 2007; Lonsdale, Hodge, \& Rose, 2009; Ng, Lonsdale, \& Hodge, 2011; Williams, Grow, Freedman, Ryan, $\&$ Deci, 1996). In addition, perceptions that significant others (e.g., coaches, sport leaders, PE teachers) provide self-initiated opportunity, meaningful rationale for advised actions, and respect for opinions and feelings may satisfy these needs. These perceptions, known as autonomy support, have been shown to be the antecedent of basic need satisfaction and self-determined motivation among athletes and PE students (Adie, Duda, \& Ntoumanis, 2008; Barkoukis, Hagger, Lambropoulos, \& Tsorbatzoudis, 2010; Reinboth, Duda, \& Ntoumanis, 2004).

Likewise, in the sport injury context, studies have provided preliminary support for the relationship between perceived autonomy support provided by a sports team's physician and athletes' self-determined motivation and adherence to sport injury rehabilitation (i.e., a pivotal element for the prevention of reinjury in sport; Chan, Lonsdale, Ho, Yung, \& Chan, 2009). There is also support for the association between self-determined motivation, intentions, adaptive social cognitive beliefs with respect to injury-preventive behavior in sport (Chan \& Hagger, 2012) and occupational settings (Chan \& Hagger, 2011). However, no previous study has simultaneously tested the links between perceived autonomy support from the coach and self-determined motivation in sport and injury prevention contexts among elite athletes.

\section{The Trans-Contextual Process}

Another important gap in the research is that coaches are often perceived to be less relevant to injury issues in comparison with medical professionals (Chan, Hagger, \& Spray, 2011), but they are nevertheless important because they are the professionals with whom athletes spend most of their time in a sport context. Previous qualitative research has highlighted that the external pressure from coaches may encourage athletes' acceptance of injury risk or safety violation (Howe, 2004; Roderick \& Waddington, 2000). Furthermore, a growing body of research has supported the view that the self-determined motivation reinforced by perceived autonomy support is a strong predictor of individuals' attitude, normative beliefs, and perception of control toward health behaviors (Hagger \& Chatzisarantis, 2009b), such as injury-preventive actions (Chan \& Hagger, 2011, 2012a, 2012c). In an injury context these beliefs may include safety commitment, prioritization of injury prevention, attitude toward safety violation, and the personal beliefs that injury is inevitable, worth talking about, and not terrifying (Rundmo \& Hale, 2003). These phenomena may highlight the central theoretical tenet in our study, namely, "the trans-contextual effect," in which motivation from one behavioral context (i.e., sport) affects the motivational and belief patterns in another related context (i.e., sport injury prevention).

A key premise of this transcontextual effect is that the transfer of motivation is generalizable across related behaviors. This is consistent with many social psychological theories that explain the generalizability of psychological constructs (e.g., self-concept, and enjoyment) across contexts at different levels of generality (Goetz, Hall, Frenzel, \& Pekrun, 2006; Marsh \& Yeung, 1998). Similarly, empirical research based on the SDT has also revealed that the global motivational orientation (i.e., the motivation applies to all life domains) and the specific learning motivation 
of students are reciprocally transferrable (Guay, Mageau, \& Vallerand, 2003). A central tenet is that the motivational processes that lead to behavioral engagement are applicable to multiple behavioral contexts at the same level of hierarchy. For instance, athletes engaged in sport performance training and competitions in a sport context, and the behaviors relevant to this context, would be different to those in the context of sport injury prevention where athletes undertake injury-preventive behaviors, such as stretching, attending massage or physiotherapy sessions, and neuromuscular training - all behaviors that are not directly relevant to training or preparation for sport performance. However, according to the transcontextual effect of motivation, behavior in these two contexts might be compatible in terms of the type and quality of motivation experienced and the organismic goals they service (e.g., satisfaction of psychological needs and to feel autonomous in thought and action). This is because motivation is likely to be governed by higher-order motivational orientations likely to influence motivation at the lower levels, but also, most importantly, because of motivational transfer at the contextual level.

The premise that motivation is transferrable across contexts is in accordance with the hierarchical model of motivation (Vallerand, 2000). According to the model, motivational orientations from SDT operate at three levels of generality (i.e., specific, contextual, and global) and are presumed to be interconnected. Motivation at contextual level (i.e., the overall motivational level of all the tasks submerged in a given context) is regarded as the bridge between motivation at specific level (motivation at the lowest level of the hierarchy that is highly dependent on time and task) and global level (motivation at the highest level of the model that is generalized and global in orientation, synonymous with general causality orientation; Deci \& Ryan, 1985a; Vallerand, 2000). This hierarchical model may help explain the transferability of motivation between sport and injury prevention.

In particular, at the global level, the two types of general causality orientations, namely, autonomy orientation and controlled orientation (Deci \& Ryan, 1985a), may serve as catalysts of the transcontextual motivational effect. Autonomy orientation refers to a relatively stable tendency of being motivated by autonomous reasons such as personal goals and interest, or to perceive events and people as autonomy supportive (i.e., provision of choice, respect of opinions, and support for competence). Whereas controlled orientation refers to the tendency to be motivated by controlled reasons such as external contingency or internal feelings of obligation, or to perceive others as controlling. These causality orientations are important dispositional determinants of self-determined motivation because autonomy orientation is more likely to lead to the satisfaction of psychological needs in comparison with controlled orientation (Hagger \& Chatzisarantis, 2011; Vallerand, 2000).

For that reason, these two types of trait-like motivational orientation not only influence motivation at the specific level directly, but also indirectly through their impact on the social environmental (e.g., perceived autonomy support, a proposed social antecedent of motivation according to SDT) and motivational factors at contextual level (Deci \& Ryan, 1985a; Vallerand, 2000). Such tenets may imply that an athlete who holds high autonomy and low controlled orientation is more likely to perceive his or her coach as autonomy supportive, and such perceptions would further elevate levels of self-determined motivation in sport, and also in other performance-optimizing activities related to sport, such as injury preven- 
tion and rehabilitation. Thus, we speculate that causality orientation may help establish the relationship between motivation in sport and motivation for sport injury prevention.

Furthermore, the transcontextual effect could be instigated by perceptions that significant others (i.e., coach) provide autonomy support to athletes for sport-related behaviors (e.g., training attendance, specific skills practice) and for behaviors related to sport injury management (e.g., warming up, stretching, strengthening exercises; Chan et al., 2011). This is because athletes' perceptions of autonomy support from coaches may not only influence self-determined motivation toward sport, but may also affect motivation for behaviors in another related context, such as sport injury rehabilitation (Chan et al., 2011) and, plausibly, in sport injury prevention. Therefore, perceived autonomy support from the coach might not only be predictive to athletes' motivation in sport, but it could also explain athletes' motivational and belief patterns of sport injury prevention.

In addition, feeling self-determined toward sport means that the athlete possesses high inherent interest and attaches personally relevant value to sport, which are means to satisfy psychological needs (Vallerand, 2000). Therefore, when an injury arises, or when faced with the prospect of future injury, athletes with high self-determined motivation are more likely to engage in injury-preventive behaviors or rehabilitation for autonomous reasons because they truly want to be able to continue to pursue their valued behavior in sport, and injury or reinjury (i.e., by rehabilitation) is a key barrier to achieving this goal (Chan \& Hagger, 2011; Chan et al., 2011). Therefore, the transcontextual transfer of motivation across sport and sport injury contexts occurs because they both service the same autonomous goal, namely, to continue to pursue engagement in an activity that satisfies psychological needs: sport. We plan to empirically test this transcontextual effect across both contexts by measuring motivation in sport and sport injury-prevention contexts.

Empirical tests of the transcontextual process of motivation have primarily focused on physical education (PE), and it was consistently found that students' self-determined motivation to be active in a PE context is transferred to the motivation toward physical activities outside school (Hagger et al., 2009). A recent study also incorporated the concepts of basic psychological need satisfaction into the model, wherein the satisfaction for autonomy and competence were found to be significant mediators of the relationship between PE perceived autonomy support from teachers' and students' motivation in PE (Barkoukis et al., 2010).

Recent evidence has confirmed the transcontextual process of motivation in health-related and safety behavior contexts. For example, a series of recent studies has supported the transfer of motivation across contexts in athletes' rehabilitation from sports injuries (i.e., motivation transferred from the sport context; Chan et al., 2011), and the prevention and rehabilitation of injuries in occupational settings (i.e., motivation transferred from the work context; Chan \& Hagger, 2011).

\section{The Present Study}

In summary, research has supported the hypothesis that self-determined forms of motivation can be transferred between related contexts, particularly for the transfer of motivation of exercise behavior from educational to leisure-time contexts. Given 
the prevalence of injuries in sport (Knowles et al., 2006) and the growing amount of research showing that psychological factors like motivation play a key role in athletes' compliance with medical advice to help recover from injury (Chan et al., 2011, 2009), it is important to investigate whether psychosocial factors from the sport context may explain athletes' motivation of injury-preventive behaviors. The overall aim of the current study is to examine a transcontextual model in which general causality orientation, and perceived autonomy support, basic need satisfaction, and self-determined motivation in sport predict motivation, beliefs, and behavior regarding sport injury prevention. The study will make an original contribution to the literature not only by bringing forth a preliminary test of SDT for sport injury prevention among elite athletes, but also by testing the transcontextual mechanism of injury-preventive motivation with the inclusion of basic need satisfaction, which is unique to the existing literature concerning health and safety (Chan \& Hagger, 2011).

In this study, we tested a number of key premises derived from SDT and the hierarchical model of motivation in a sport injury prevention context. Based on the previous literature (Chan \& Hagger, 2011; Chan et al., 2009; Vallerand, 2000), we present the following hypotheses with respect to the motivational influences on injury prevention in elite sport. First, we hypothesize that the key paths in the motivational sequence of transcontextual motivation from perceived autonomy support to motivation for sport injury prevention will be significant and positive. Specifically, we expect the following motivational sequence to be confirmed: perceived autonomy support from the coach $\rightarrow$ basic need satisfaction in sport (Mediator 1) $\rightarrow$ self-determined motivation in sport (Mediator 2) $\rightarrow$ self-determined motivation for sport injury prevention. As such, basic need satisfaction in sport and self-determined motivation in sport are hypothesized mediators within the proposed motivational sequence. Second, the constructs within the proposed motivational sequence are hypothesized to be significantly and positively predicted by autonomy orientation and negatively predicted by controlled orientation. Third, we hypothesize that self-determined motivation for sport injury prevention (Mediator 3) would be predictive of injury-related outcomes (forms significant positive associations with adherence to injury prevention, safety commitment, and injury priority, and negative associations with fatalism concerning injury prevention, attitude toward safety violation, barriers to safety communication, and injury worry), and would mediate the relationships between self-determined motivation in sport and these outcome variables.

\section{Methods}

\section{Participants}

Participants were 533 elite athletes $\left(M_{\text {age }}=16.79, S D=2.80 ; 50.30 \%\right.$ male $)$ recruited from eight elite-sport training centers within the Sichuan Province of China. They were either regional level $(15.00 \%)$, national level $(70.70 \%)$, or international level $(11.6 \%)$ athletes from 13 different sports (16.32\% swimming, $15.38 \%$ athletics, $15.01 \%$ soccer, $9.94 \%$ gymnastics, $6.94 \%$ cycling, $6.75 \%$ badminton, $5.81 \%$ volleyball, $5.25 \%$ canoeing, $4.88 \%$ diving, $4.32 \%$ tennis, $4.13 \%$ basketball, $3.56 \%$ rowing, and $1.69 \%$ windsurfing). Athletes had received elite training in their sport 
for more than 1 year (training years, $M=3.23, S D=2.15$ ). Participants on average experienced 2.49 injuries $(S D=5.11$; range from 1 to 80$)$ in the previous 6 months, a number of them $(15.80 \%)$ reported injury that currently affected their training or sport performance, and a large proportion (47.10\%) reported prior experience with a sport injury that required at least two weeks of medical attention in the previous two years. Participants and their parent or guardian signed the consent forms to acknowledge that they fully understood the procedures of the study and their participation rights (i.e., voluntary nature of participation, confidentiality of data, and freedom to withdraw from the study at any time without prejudice). Participation was completely voluntary and no inducement was given to participants. The study was approved by the Research Ethics Committee of the University of Nottingham, and supported by the Sichuan Sport Bureau and the coaches and managers of sport teams involved in the study.

\section{Measures}

To reduce the effect of common method variance (Doty \& Glick, 1998) and the response burden to the participants, psychological measures of the study were distributed across two questionnaires administered by a research assistant to the participants after they had finished their training sessions. The consent forms and the completed questionnaires were collected within 2 days of the questionnaire administration. The first and second questionnaires were administered on two separate occasions, with at least one week apart. The first questionnaire comprised scales measuring demographic variables (i.e., gender, age, years in sport), general causality orientation, basic need satisfaction in sport, sport motivation, and perceived autonomy support from coaches. The second questionnaire included items to measure self-determined motivation, personal beliefs, and adherence with respect to injury prevention. ${ }^{1}$ The research assistant delivered the second questionnaire to the participants across the whole week to enhance the response rate for this 1-week follow-up, and all the participants managed to complete both questionnaires. The questionnaires were presented in Chinese, the native language of the participants, and took 10-15 min to complete. Items and instructions were either translated using back-translation procedures from their original English versions or, where available, adapted from Chinese versions developed in previous studies. Details of the measures we used are described below, and their example English items and Likert-scale anchors are given in the Appendix.

\section{Autonomy Support, Basic Need Satisfaction in Sport, and Sport Motivation.}

Perceived autonomy support from the coach was measured using an adapted version of the Health Care Climate Questionnaire (HCCQ; Williams \& Deci, 1996). The HCCQ is a single-dimension scale that has frequently been adopted to assess the perceived autonomy support in health contexts (Adie et al., 2008; Reinboth et al., 2004), and we adopted the six-item Chinese version developed in a previous study (Chan et al., 2011).

We used the 21-item Chinese version of the Basic Need Satisfaction in Sport Scale (Ng et al., 2011) to assess the three basic psychological needs of athletes, including autonomy, relatedness, and competence (Deci \& Ryan, 1985b). We developed an overall basic need satisfaction factor ${ }^{2}$ indicated by the means of the autonomy (10 items), competence (5 items), and relatedness (6 items) items. 
We used the Chinese version (Chan et al., 2011) of the Behavioral Regulation in Sport Questionnaire (BRSQ; Lonsdale, Hodge, \& Rose, 2008) to measure autonomous and controlled forms of motivation from SDT. We computed a single index ${ }^{3}$ of self-determined sport motivation by summing the weighted scores of autonomous and controlled forms of motivation along the SDT continuum (Lonsdale et al., 2009).

Motivation for Injury Prevention. The Treatment Self-Regulation Questionnaire (TSRQ; Williams et al., 1996) was used to measure participants' overall autonomous motivation to engage in recommended health-enhancing behaviors. The TSRQ has been adapted for use in different health contexts, such as prescribed weight control or exercise programs (Levesque et al., 2007), and received strong evidence for its score reliability and validity. In this study, we used the sport injury prevention version of TSRQ (Chan \& Hagger, 2012) to measure autonomous (six items) and controlled motivation (six items) for sport injury prevention. The relative autonomy index for sport injury prevention was the sum of the weighted scores of autonomous (weight $=+1$ ) and controlled (weight $=-1$ ) items (Fortier et al., 2007).

Adherence. Following previous research examining injury prevention and rehabilitation motivation in occupational settings (Chan \& Hagger, 2011), we developed nine items to measure the self-reported adherence of sport injury prevention. Participants reported how frequently (five items) and how much effort (four items) they invested in engaging in injury-preventive behaviors (e.g., achieving safety objectives, improving physical or mental conditions, caring for an old injury, seeking advice from others; Bahr \& Engebretsen, 2009; Emery \& Tyreman, 2009).

Injury Beliefs. We adapted 21 items from the Manager Safety Attitude Questionnaire (MSAQ; Rundmo \& Hale, 2003) to assess salient injury and safety related beliefs shared by athletes, including safety commitment (three items; the degree of commitment toward safety guidelines in sport), injury priority (two items; the extent to which injury prevention is more important than other aspects in sport), fatalism concerning injury prevention (five items; the belief about the inevitable nature of sport injury), attitudes toward safety violation (five items; acceptance toward the violation of safety regulation in sport), barriers to safety communication (two items; the perceived difficulty of talking to others about sport injury prevention), and injury worry (four items; the degree of worry toward sport injury). The adaptation was done by firstly screening the dimensions of MSAQ applicable to elite sport; secondly replacing the terms "job," "work," and "career," by "sport" in the items; and thirdly reexamining their comprehensiveness and face validity.

General Causality Orientation. The General Causality Orientation Scale (GCOS; Deci \& Ryan, 1985a) was adopted to assess the dispositional autonomy (12 items) and controlled (12 items) orientations of individuals. This study adopted the Chinese version of GCOS developed in a previous study among Taiwanese athletes (Wu \& Hwang, 2000).

\section{Analysis}

Variance-based structural equation modeling (VB-SEM) was employed to test the hypothesized model using the SmartPLS 2.0 statistical software (Ringle, Wende, 
\& Will, 2005). To estimate latent factor scores and correlations, VB-SEM adopts a partial least-squares algorithm, which is supposed to be distribution free (i.e., the estimation is not affected by the complexity of the model, small sample size, or nonnormality of the data). Therefore, it was unlike the typical covariance-based SEMs, which perform model estimation by using an ordinary least-squares algorithm (Reinartz, Haenlein, \& Henseler, 2009). We evaluated the fit of the model using a number of indices of convergent and discriminant validity from the measurement model. Convergent validity was considered acceptable when the Cronbach's alpha and the composite score reliability of each dimension were higher than .70 , the average variance extracted (AVE) for each factor was higher than 0.50 , and the factor loading of each item on its corresponding factor was higher than .70 (Barclay, Thompson, \& Higgins, 1995). Discriminant validity was supported when the factor loadings of an item on its own construct was higher than its cross-loadings on the other constructs and the square root of the AVE of any construct was higher than its correlation with other constructs (Chin, 1998). Moreover, a bootstrapping resampling technique with 5000 replications was used to reveal reliable averaged path estimates and associated significance levels.

We also conducted a mediation analysis (Zhao, Lynch, \& Chen, 2010) to examine whether the proposed mediation effects ${ }^{4}$ were present in our hypothesized motivational sequence among the study constructs. Mediation was supported when the independent variable (IV) exerted a significant direct and indirect effect computed by the Aroian test (Aroian, 1947) on the dependent variable (DV), and the direct effect of the IV on the DV was not significant (indication of full mediation) or significantly reduced (indication of partial mediation) when controlling for the effect of the mediator. The ratio between indirect and total effect was computed to indicate the proportion of the total effect explained by the mediator in the $\mathrm{IV} \rightarrow \mathrm{DV}$ path.

\section{Results}

\section{Preliminary Analyses}

The convergent and discriminant validity indices generally met the criteria for acceptable score reliability of VB-SEM (see the Analysis section for the criteria). Regarding convergent validity, composite reliability scores ranged from .72 to .93 , AVE values ranged from .55 to .74 , and factor loadings ranged from .63 to .91 . Cronbach's alpha coefficients ranged from .70 to .92, apart from that for the injury priority $(\alpha=.65)$, barriers to safety communication $(\alpha=.66)$, and injury worry $(\alpha=.68)$ scales. Yet, all the alpha coefficients were above the published criteria of internal consistency (i.e., .60; Cronbach, 1951). For discriminant validity, items had factor loadings higher than 70 (median factor loading $=.79$ ), and the factor loadings were higher than their cross-loadings on the other factors by an average difference of .37 . The square root of the AVE for each construct was larger than the construct correlation with other factors by an average difference of .33. Table 1 displays the correlation matrix, distributions (mean and $S D$ ), and internal score reliability statistics (Cronbach's alpha, composite score reliability) of the variables. 


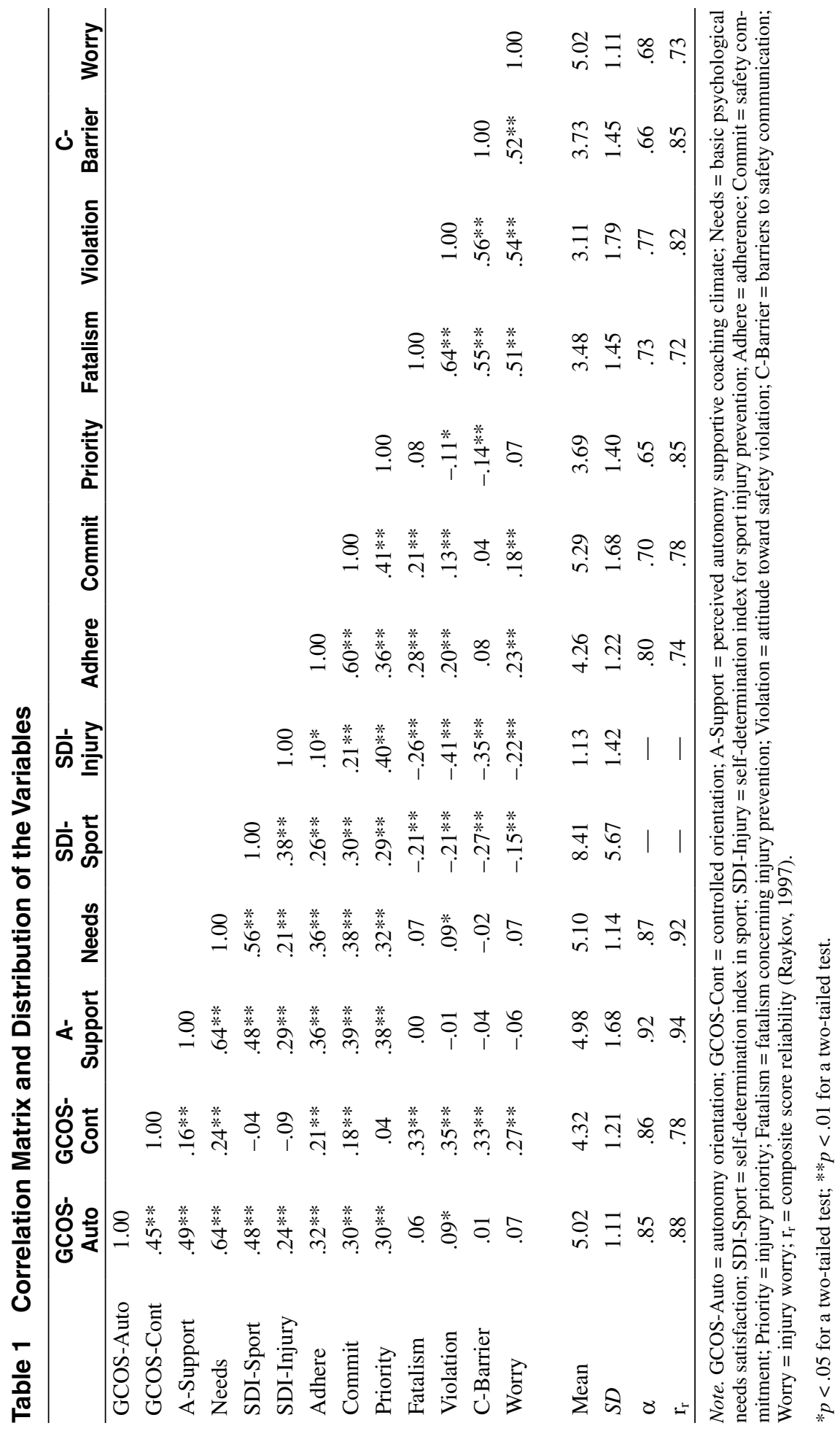




\section{Path Estimates}

The mean estimates generated from the bootstrapped resampling method fully supported our hypothesized motivational sequence (see Figure 1). The paths included in our sequence: perceived autonomy support $\rightarrow$ basic need satisfaction (Path 1) $\rightarrow$ self-determined motivation in sport (Path 2) $\rightarrow$ self-determined motivation (Path 3 ) for sport injury prevention were all positive and significant as predicted. With regards to the independent variables at global level, while there were positive effects for autonomy orientation on perceived autonomy support, basic need satisfaction, self-determined motivation in sport, and self-determined motivation for sport injury prevention as expected, the corresponding effects of controlled orientation were not significant. Self-determined motivation for sport injury prevention formed significant positive associations with adherence, safety commitment, and injury priority, and negative relationships with fatalism concerning injury prevention, attitude toward safety violation, barriers to safety communication, and injury worry.

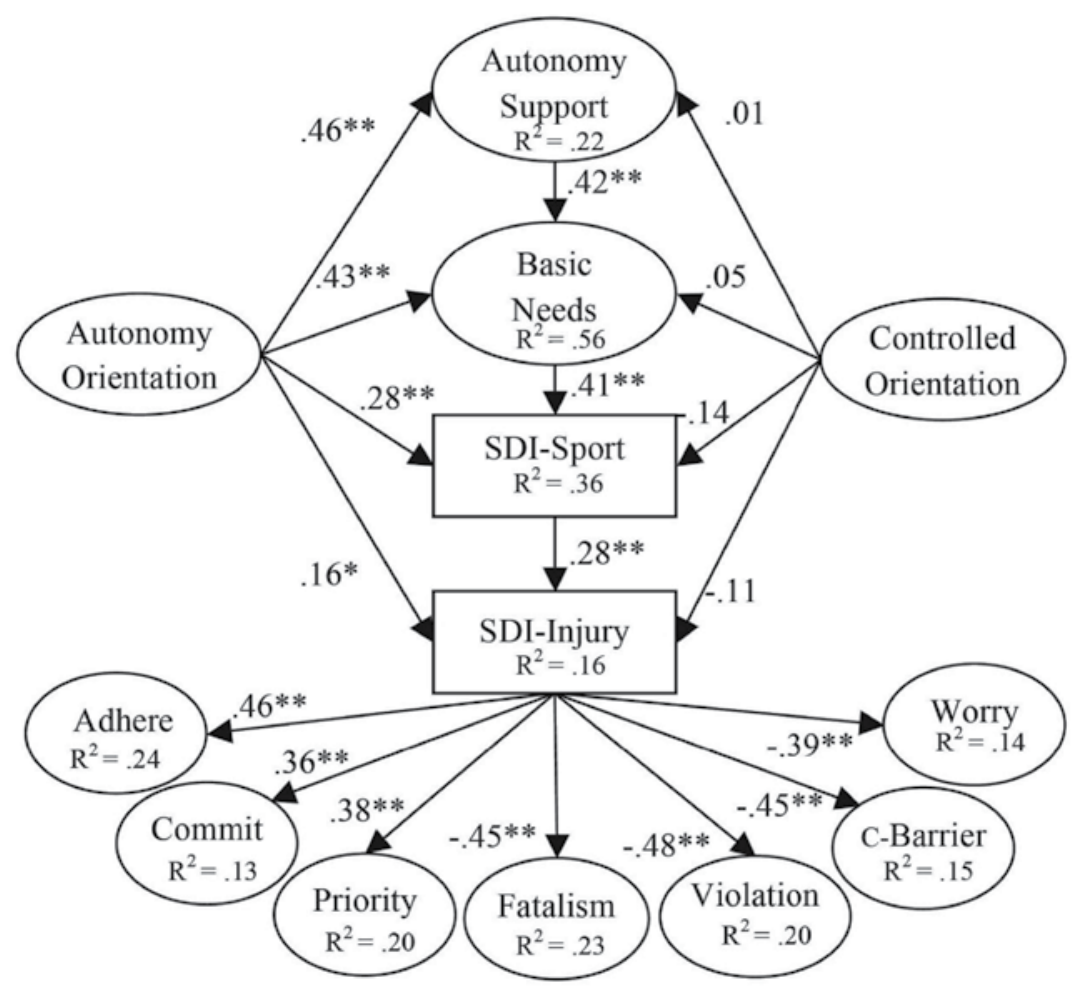

Figure 1 - Path estimates for the trans-contextual motivation of sport injury prevention. Note . Autonomy support $=$ perceived autonomy support; SDI-Sport = self-determination index in sport; SDI-Injury = self-determination index for sport injury prevention; Adhere $=$ adherence; Commit $=$ safety commitment; Priority $=$ injury priority; Fatalism $=$ fatalism concerning injury prevention; Violation $=$ attitude toward safety violation; $\mathrm{C}$-Barrier $=$ barriers to safety communication; Worry $=$ injury worry. ${ }^{*} p<.05$ for a two-tailed test; ${ }^{* *} p<$ .01 for a two-tailed test. 


\section{Mediation Analysis}

Mediation analyses supported the effects for two of our hypothesized mediators. Basic need satisfaction (Mediator 1) partially mediated the relationship between perceived autonomy support and self-determined motivation in sport. Self-determined motivation for sport injury prevention (Mediator 3) was shown to be a significant (partial) mediator of the effects of self-determined motivation in sport on all the outcome variables (i.e., adherence, safety commitment, and injury priority, fatalism concerning injury prevention, attitude toward safety violation, barriers to safety communication, and injury worry). However, self-determined motivation in sport (Mediator 2) did not mediate the relationship between basic need satisfaction and self-determined motivation for sport injury prevention as hypothesized, but its mediating effect was significant in the relationship between perceived autonomy support and self-determined motivation for sport injury prevention (see Table 2 for details).

\section{Discussion}

The present study is the first to examine the transcontextual process of motivation within a competitive sport context, where sport motivation "transfer" into an injury-preventive motivation. To summarize, our findings supported our three key hypothesized sets of relations among the study variables: (1) the transcontextual process of motivation between the sport and sport injury prevention context, (2) the effects of general causality orientations on the transcontextual effect, and (3) the prediction of self-determined motivation for sport injury prevention on the behavioral and belief outcomes. Overall, the present research provided additional supporting evidence for the proposed transcontextual effects of motivation derived from SDT and the hierarchical model of motivation.

\section{The Trans-Contextual Effect}

Unlike the previous studies of Chan and Hagger (2011), we controlled the effect of global-level-motivation (i.e., the general causality orientation) on the relationship between motivations in two related contexts. However, we obtained a pattern of results consistent with their findings (Chan \& Hagger, 2011), indicating that athletes' motivation in sport is related to the quality and magnitude of their motivation for injury prevention within sport. In addition, self-determined motivation in sport predicted self-determined motivation for sport injury prevention in a higher magnitude than the two forms of general causality orientation did, thus it might depict that the transcontextual mechanism was not merely driven by individuals' personality trait of motivation, but it was also be channeled by the transfer of motivation between related contexts under the same hierarchy according to our speculation.

This implies that athletes with autonomous motivational orientations in sport are more likely to be motivated to prevent sport injury for autonomous reasons such as finding injury prevention optimally challenging and highly relevant to achieve life goals, as opposed to controlled reasons such as to avoid upsetting others (e.g., coach, physiotherapist). This finding is particularly important for the promotion of injury prevention within the current competitive environment in sport where performance and winning usually override actions or decisions that aim to reduce the likelihood or severity of injury (Roderick \& Waddington, 2000). 


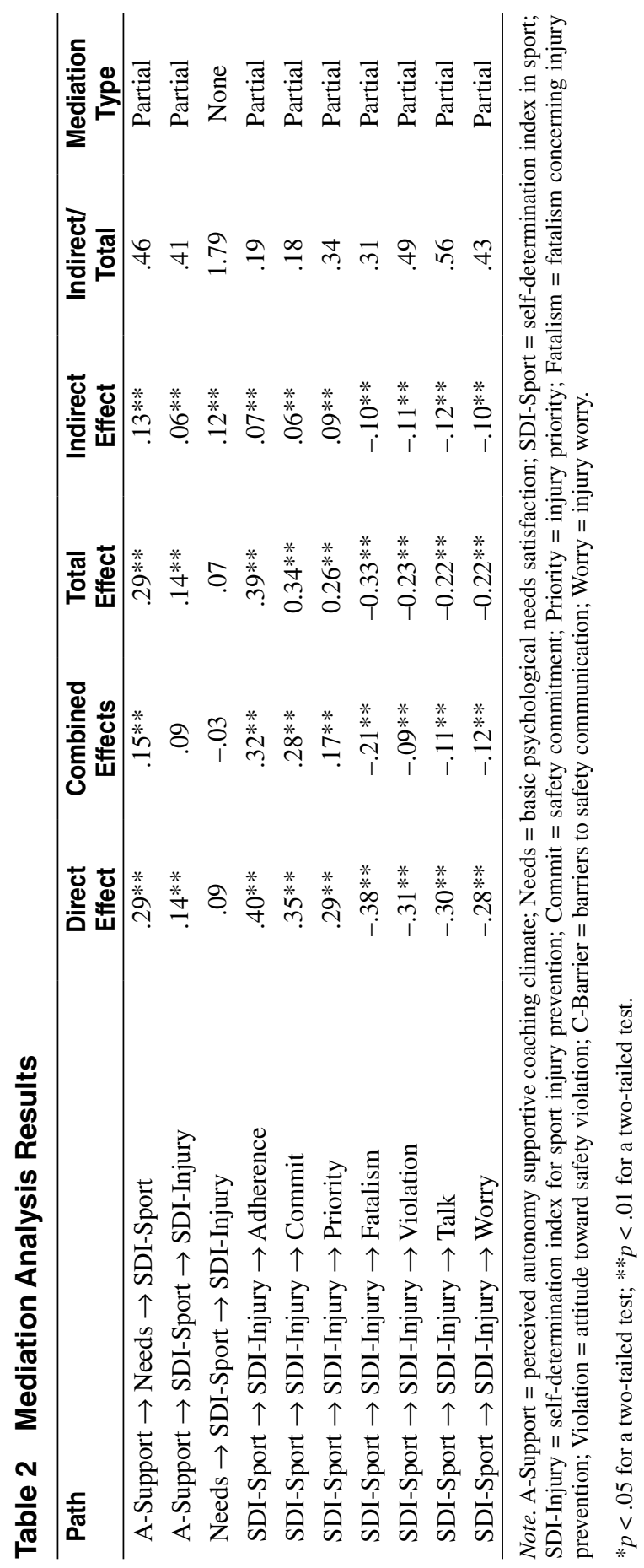


Similarly, controlled motivation in sport may heighten the likelihood of endorsing controlled motivation for sport injury prevention. Thus, the external focus among those with controlling motivational orientations in sport (e.g., "I am training hard because I don't want to disappoint my coach"), according our results, may give rise to the endorsement of controlling motives for sport injury prevention (e.g., "I wear a cycling helmet only because it is the rule"), which is likely to further reduce athletes' initiative and sense of ownership over injury-preventive actions. In other words, the more the competitive environment emphasizes extrinsic reasons such as winning and external contingencies associated with the game (i.e., the promotion of controlled motives in sport), the less the players might regard the prevention of injury or reinjury as being a meaningful and personally fulfilling experience. This may explain the social process that leads to the consolidation of the "playing-hurt" or risk-averse culture in sport (Roderick \& Waddington, 2000) and provide a plausible reason why the increasing professionalism in sport could be associated with higher incidence of sport injury (Howe, 2004). Indeed, research using approaches from sport policy and sociology should be conducted to further examine these arguments alongside the current evidence.

Likewise, the amount of variance explained in the self-determined motivation for injury prevention was comparable to a previous study in an occupational context (Chan \& Hagger, 2011). The size of the effect was small, and this is probably because the current study computed a single composite score (i.e., the relative autonomy index) to represent overall self-determined motivation instead of making a distinction between autonomous and controlled forms of motivation. This approach though reduced the complexity of the model, making the results more interpretable, the power of prediction could have been weakened because the measurement errors of self-determined motivation in both contexts was heightened cumulatively while the independent predictive validity of different behavioral regulations did not accumulate to produce stronger predictive power. This could explain why a higher amount of variance in self-determined motivation for sport injury rehabilitation was explained by autonomous motivation and controlled motivation in sport (Chan et al., 2011). Another explanation could be the presence of an injury-tolerance culture in a sport injury prevention context (Howe, 2004; Roderick \& Waddington, 2000 ) as noted previously. Such a maladaptive culture might plausibly lead some athletes to accept sport injury and the risk of injury as "part of the game" (Howe, 2004; Roderick \& Waddington, 2000), and in this case, self-determined motivation in sport might ironically become an antecedent of self-determined motivation for risk-taking behaviors, rather than for the behaviors of injury prevention and safety. This possibility is an interesting avenue for future research, and it also raises the importance of safety education in elite sport.

\section{Perceived Autonomy Support and Basic Need Satisfaction}

Consistent with SDT (Deci \& Ryan, 1985b) and previous research (Adie et al., 2008; Reinboth et al., 2004; Vallerand, 2000), perceived autonomy support from the coach was shown to be a positive predictor of basic need satisfaction which further associated with the facilitation of self-determined motivation in sport. However, it is noteworthy that sport motivation was only significant in mediating the direct path between autonomy support and motivation for sport-injury prevention, but not the path between basic need satisfaction and motivation for sport-injury prevention. 
This is inconsistent with our hypothesis that basic need satisfaction would be a more proximal predictor of self-determined motivation than perceived autonomy support.

Nevertheless, athletes' basic need satisfaction in sport is not equivalent to the corresponding perception in the injury prevention context, so injury-preventive motivation would potentially be dependent on whether the athletes' basic psychological needs were also fulfilled in the injury prevention context (Keats, Emery, \& Finch, 2012). We bear in mind that perceived autonomy support is a contextual-level determinant of motivation according to Vallerand's (2000) hierarchy that may carry its impact down to the specific level of generality. Thus, an autonomy-supportive coaching climate might also involve the provision of support for psychological needs regarding players' injury-preventive behaviors, and it could carry a more salient effect on motivation for sport injury prevention. Future research should scrutinize the role of significant others' (e.g., coaches and team physicians) actual support for the basic psychological needs of athletes with regard to injury prevention.

\section{Motivation for Sport Injury Prevention}

In this study, we measured a series of outcomes associated with the self-determined motivation for sport injury prevention, and our findings were consistent with previous studies that have applied SDT to explain injured athletes' intentions to follow, and actual adherence to, medical guidelines (Chan et al., 2011, 2009). Self-determined motivation was not only associated with athletes' adherence to injury prevention, it was also shown to be a strong predictor of a number of beliefs concerning safety and injury prevention, which were consistent with the findings of previous studies that predicted individuals' social cognitive beliefs by selfdetermined motivation for injury prevention in sport (Chan \& Hagger, 2012) and occupational contexts (Chan \& Hagger, 2011).

These studies examined beliefs from the theory of planned behavior (Ajzen, 1985). In contrast, the current study used the MSAQ to measure a set of attitudebased beliefs that were more generalized in measurement and conceptualization. These measures had some commonalities with the beliefs outlined in the theory of planned behavior and other attitude theories in that they serve as antecedents of intentional behavior (Rundmo \& Hale, 2003). The hypothesized prediction of these attitude-based beliefs by the motivational variables in the current study is consistent with Deci and Ryan's (1985b) original contention that people form attitudes and beliefs consistent with motivational orientations from SDT. According to SDT, these beliefs drive future behavioral engagement because they inform the formation of intentions to do the behavior in the future in accordance with many attitude or belief-based social cognitive theories like the TPB. Of course, these are not the only types of beliefs people might hold with respect to sport injury. There may be beliefs incompatible with SDT motives. For example, a cyclist might think that downhill racing without wearing a helmet can be dangerous (a positive belief of sport injury prevention), but the primary reason to wear a helmet in a competition could be that it is the rule (a controlled motive). This is why the relationships between beliefs and SDT constructs, although strong, are not perfect, thus leaving some variance in the beliefs unexplained (Chan \& Hagger, 2012b; Hagger \& Chatzisarantis, 2009b). Therefore, the current data are consistent with previous research that has shown beliefs from social-cognitive theories like the theory of planned behavior mediate the effects of motivational orientations from SDT on intention and behavior (Chan 
\& Hagger, 2012b; Hagger \& Chatzisarantis, 2009b), and these reflect the process by which SDT motives affect variables implicated in decisions to engage in the behavior in future through intentions. This is consistent with SDT (Deci \& Ryan, 1985b), which suggests that motives drive the formation of beliefs that serve to perpetuate experiences of autonomy and competence. Even though we did not examine the mediating role of belief-based variables on the motivation-behavior pathway as has been done previously in models integrating SDT and attitude theories like the theory of planned behavior (Chan \& Hagger, 2012; Hagger \& Chatzisarantis, 2009b), our findings may inform future tests of the effects of generalized motives from SDT on injury prevention mediated by proximal social-cognitive variables like beliefs.

\section{General Causality Orientations}

As expected, autonomy orientation formed positive associations with perceived autonomy support, basic need satisfaction, and self-determined motivation in both contexts (i.e., sport, injury prevention), but the proposed negative predictions by controlled orientation were not evident. Therefore, these findings suggest that autonomy orientation is more effective than controlled orientation for establishing connections between motivation at different contexts and levels of generality. It supports the premises from SDT (Deci \& Ryan, 1985b) and the "top-down effect" of Vallerand's (2000) model that generalized orientations act as distal influences on motivational orientations in a number of contexts. The reason for the nonsignificant effects for controlled orientation is that a controlling and need-thwarting environment is not synonymous with the absence of perceived autonomy support and basic need satisfaction (Bartholomew, Ntoumanis, Ryan, \& Thogersen-Ntoumani, 2011). With these considerations in mind, the development of reliable measures for constructs such as need-thwarting and controlling behaviors is crucial for future research to uncover the darker side of social and motivational patterns within an injury-prevention context (Ryan \& Deci, 2000).

\section{Limitation and Further Directions}

Apart from the commendations above, there are some limitations of this study that need to be addressed and we hope that these will stimulate future research in this area. With a cross-sectional design, we were unable to draw definite conclusions about the causal and temporal order of the variables within the model, and a lack of follow-up assessments and control for past behavior also hindered our understanding of how changes in injury-preventive behavior initiated by motivation and perceived autonomy support are related to the change of sport injury incidence over time. However, the evidence from the current study could form the basis of an experimental or intervention study in which the constructs from the integrated model of transcontextual motivation are independently manipulated, providing a robust test of the differential effects on the various components, and the evidence regarding the discriminant validity, and the causal and meditational processes of the model. Despite of real challenges in terms of data attrition in the longitudinal design, the difficulty in manipulating the motivational variables while holding other variables constant, and the effects of error artifacts (e.g., noncompliance, treatment fidelity, mere measurement), such methods will be an avenue for future research into the psychosocial aspects of sport injury prevention. 
Moreover, the implementation of a number of adapted measures and the comprehensiveness of the items for the youth participants in this study might undermine the precision of measurement. Some of the adapted dimensions of the MSAQ constructs (e.g., injury priority, barriers to safety communication) measured by small number of items might have restricted coverage of the entire construct. In addition, a few reliability scores (i.e., coefficient alphas) of these constructs were lower than the cutoff criterion for VB-SEM. These scores are often regarded as the lower boundary of score reliability and could have been affected by itemper-dimension and the total number of factors within the scale (Cortina, 1993; Raykov, 1997). On this basis, we should interpret our findings with caution due to these measurement limitations. Further studies should examine the face validity and test-retest reliability of the scales within the samples of different age groups, and should continue developing and refining the scales by multimethod (e.g., qualitative-quantitative) and cross-cultural approaches (Hagger \& Chatzisarantis, 2009a). Finally, using self-report assessment of adherence might embrace problems associated with social desirability and memory bias. Even though these factors would likely inflate the measurement error and attenuate the path estimates in the model than increase the potential for type-I error (Williams et al., 1996), future studies should develop objective ways to measure adherence to injury-preventive behaviors and behaviors related to safety violation in sport.

\section{Conclusions}

In conclusion, our study presented a preliminary test of the dispositional, psychosocial, and motivational processes associated with sport injury prevention. Results revealed that general causality orientation predicts the psychological components of the proposed transcontextual transfer of motivation, and athletes' self-determined motivation in sport is related to the endorsement for motivation in a different, but related, sport context. Thus, the associations between motivational factors at the global, contextual, and specific levels of generality convey important information for sport policy, team management, and coaching strategies to build up an injuryfree environment for athletes.

\section{Notes}

1. The second questionnaire also comprised measures of the variables from the theory of planned behavior (TPB; Ajzen, 1985), which was reported in another study (Chan \& Hagger, 2012) concerning about the theoretical integration between SDT and TPB. The study used a different theoretical framework, and was set up to test hypotheses related to research questions independent of the present investigation. Self-determined motivation for sport injury prevention was the only variable in this study included in our analysis.

2. Alternative models with autonomy ( $r$ with competence $=.77$ ), competence ( $r$ with relatedness $=.62)$, and relatedness $(r$ with autonomy $=.73)$ as three separate basic need satisfaction latent factors were employed in our analyses. Although the factors demonstrated acceptable level of discriminant validity, the paths and mediation analysis results were highly consistent across the three factors. To reduce the complexity of the model, we derived a single score representing the total basic psychological need satisfaction from these three factors. However, the results of the analyses using the alternative models can be obtained from the first author on request. 
3. The index was computed by summing weighted scores of the external regulation (weight $=$ -2 ; four items), introjection (weight $=-1$; four items), identification (weight $=+1$; four items), integration (weight $=+1$; four items), and intrinsic motivation (weight $=+2$; four items) items from the BRSQ (Lonsdale et al., 2009).

4. Four proposed mediation effects (as shown by the number of mediators) are presented in the hypothesized motivational sequence: Perceived autonomy support $\rightarrow$ basic need satisfaction (Proposed Mediator 1) $\rightarrow$ self-determined motivation in sport (Proposed Mediator 2) $\rightarrow$ selfdetermined motivation for sport injury prevention (Proposed Mediator 3 ) $\rightarrow$ outcome variables, with the two causality orientations as covariates.

\section{References}

Adie, J.W., Duda, J.L., \& Ntoumanis, N. (2008). Autonomy support, basic need satisfaction and the optimal functioning of adult male and female sport participants: A test of basic needs theory. Motivation and Emotion, 32, 189-199. doi:10.1007/s11031-008-9095-z

Ajzen, I. (1985). From intentions to actions: A theory of planned behavior. In J. Kuhl \& J. Beckmann (Eds.), From intentions to actions: A theory of planned behavior (pp. 11-39). Berlin: Springer.

Aroian, L.A. (1947). The probability function of the product of two normally distributed variables. Annals of Mathematical Statistics, 18, 265-271. doi:10.1214/aoms/1177730442

Bahr, R., \& Engebretsen, L. (Eds.). (2009). Sports injury prevention: Olympic handbook of sports medicine. Oxford: Blackwell.

Barclay, D., Thompson, R., \& Higgins, C. (1995). The partial least squares (pls) approach to causal modeling: Personal computer adoption and use an illustration. Technology Studies, 2, 285-309.

Barkoukis, V., Hagger, M.S., Lambropoulos, G., \& Tsorbatzoudis, H. (2010). Extending the trans-contextual model in physical education and leisure-time contexts: Examining the role of basic psychological need satisfaction. The British Journal of Educational Psychology, 80, 647-670. PubMed doi:10.1348/000709910X487023

Bartholomew, K.J., Ntoumanis, N., Ryan, R.M., \& Thogersen-Ntoumani, C. (2011). Psychological need thwarting in the sport context: Assessing the darker side of athletic experience. Journal of Sport \& Exercise Psychology, 33, 75-102. PubMed

Chan, D.K.C., \& Hagger, M.S. (2012a). Autonomous forms of motivation underpinning injury prevention and rehabilitation among police officers: An application of the trans-contextual model. Motivation and Emotion, 36(3), 349-364. doi:10.1007/s11031-011-9247-4

Chan, D.K.C., \& Hagger, M.S. (2012b). Self-determined forms of motivation predict sport injury prevention and rehabilitation intentions. Journal of Science and Medicine in Sport, 15(5), 398-406. doi:10.1016/j.jsams.2012.03.016

Chan, D.K.C., \& Hagger, M.S. (2012c).Theoretical integration and the psychology of sport injury prevention. Sports Medicine (Auckland, N.Z.), 42(9), 725-732. PubMed doi:10.2165/11633040-000000000-00000

Chan, D.K.C., Hagger, M.S., \& Spray, C.M. (2011). Treatment motivation for rehabilitation after a sport injury: Application of the trans-contextual model. Psychology of Sport and Exercise, 12, 83-92. doi:10.1016/j.psychsport.2010.08.005

Chan, D.K., Lonsdale, C., Ho, P.Y., Yung, P.S.H., \& Chan, K.M. (2009). Patient motivation and adherence to post-surgery rehabilitation exercise recommendations: The influence of physiotherapists' autonomy supportive behaviors. Archives of Physical Medicine and Rehabilitation, 90, 1977-1982. PubMed doi:10.1016/j.apmr.2009.05.024

Chin, W.W. (1998). Issues and opinion on structural equation modeling. Management Information Systems Quarterly, 22, 7-16.

Cortina, J.M. (1993). What is coefficient alpha?: An examination of theory and applications. The Journal of Applied Psychology, 78, 98-104. doi:10.1037/0021-9010.78.1.98 
Cronbach, L. (1951). Coefficient alpha and the internal structure of tests. Psychometrika, 16, 297-334. doi:10.1007/BF02310555

Deci, E.L., \& Ryan, R.M. (1985a). The General Causality Orientations Scale: Self-determination in personality. Journal of Research in Personality, 19, 109-134. doi:10.1016/00926566(85)90023-6

Deci, E.L., \& Ryan, R.M. (1985b). Intrinsic motivation and self-determination in human behavior. New York: Plenum.

Doty, D.H., \& Glick, W.H. (1998). Common methods bias: Does common methods variance really bias results? Organizational Research Methods, 1, 374-406. doi:10.1177/109442819814002

Emery, C.A., \& Tyreman, H. (2009). Sport participation, sport injury, risk factors and sport safety practices in Calgary and area junior high schools. Paediatrics and Child Health (Oxford), 14, 439-444. PubMed

Fortier, M.S., Sweet, S.N., O’Sullivan, T.L., \& Williams, G.C. (2007). A self-determination process model of physical activity adoption in the context of a randomized controlled trial. Psychology of Sport and Exercise, 8, 741-757. doi:10.1016/j.psychsport.2006.10.006

Goetz, T., Hall, N.C., Frenzel, A.C., \& Pekrun, R. (2006). A hierarchical conceptualization of enjoyment in students. Learning and Instruction, 16, 323-338. doi:10.1016/j. learninstruc.2006.07.004

Guay, F., Mageau, G.A., \& Vallerand, R.J. (2003). On the hierarchical structure of self-determined motivation: A test of top-down, bottom-up, reciprocal, and horizontal effects. Personality and Social Psychology Bulletin, 29, 992-1004. PubMed doi:10.1177/0146167203253297

Hagger, M.S., \& Chatzisarantis, N.L.D. (2009a). Assumptions in research in sport and exercise psychology. Psychology of Sport and Exercise, 10, 511-519. doi:10.1016/j. psychsport.2009.01.004

Hagger, M.S., \& Chatzisarantis, N.L.D. (2009b). Integrating the theory of planned behaviour and self-determination theory in health behaviour: A meta-analysis. British Journal of Health Psychology, 14, 275-302. PubMed doi:10.1348/135910708X373959

Hagger, M.S., \& Chatzisarantis, N.L.D. (2011). Causality orientations moderate the undermining effect of rewards on intrinsic motivation. Journal of Experimental Social Psychology, 47, 485-489. doi:10.1016/j.jesp.2010.10.010

Hagger, M.S., Chatzisarantis, N.L.D., Hein, V., Soos, I., Karsai, I., Lintunen, T., . ... (2009). Teacher, peer and parent autonomy support in physical education and leisure-time physical activity: A trans-contextual model of motivation in four nations. Psychology \& Health, 24, 689-711. PubMed doi:10.1080/08870440801956192

Howe, D. (2004). Sport, professionalism, and pain: Ethnographies of injury and risk. London: Routledge.

Keats, M.R., Emery, C.A., \& Finch, C.F. (2012). Are we having fun yet?: Fostering adherence to injury preventive exercise recommendations in young athletes. Sports Medicine (Auckland, N.Z.), 42, 175-184. PubMed doi:10.2165/11597050-000000000-00000

Knowles, S.B., Marshall, S.W., Bowling, J.M., Loomis, D., Millikan, R., Yang, J.Z., . ... (2006). A prospective study of injury incidence among North Carolina high school athletes. American Journal of Epidemiology, 164, 1209-1221. PubMed doi:10.1093/ aje/kwj337

Levesque, C.S., Williams, G.C., Elliot, D., Pickering, M.A., Bodenhamer, B., \& Finley, P.J. (2007). Validating the theoretical structure of the Treatment Self-Regulation Questionnaire (TSRQ) across three different health behaviors. Health Education Research, 22, 691-702. PubMed doi:10.1093/her/cyl148

Lonsdale, C., Hodge, K., \& Rose, E. (2009). Athlete burnout in elite sport: A selfdetermination perspective. Journal of Sports Sciences, 27, 785-795. PubMed doi:10.1080/02640410902929366 
Lonsdale, C., Hodge, K., \& Rose, E.A. (2008). The Behavioral Regulation in Sport Questionnaire (BRSQ): Instrument development and initial validity evidence. Journal of Sport \& Exercise Psychology, 30, 323-355. PubMed

Marsh, H.W., \& Yeung, A.S. (1998). Top-down, bottom-up, and horizontal models: The direction of causality in multidimensional, hierarchical self-concept models. Journal of Personality and Social Psychology, 75, 509-527. PubMed doi:10.1037/0022-3514.75.2.509

McGlashan, A.J., \& Finch, C.F. (2010). The extent to which behavioural and social sciences theories and models are used in sport injury prevention research. Sports Medicine (Auckland, N.Z.), 40, 841-858. PubMed doi:10.2165/11534960-000000000-00000

Ng, J.Y.Y., Lonsdale, C., \& Hodge, K. (2011). The Basic Needs Satisfaction in Sport Scale (BNSSS): Instrument development and initial validity evidence. Psychology of Sport and Exercise, 12, 257-264. doi:10.1016/j.psychsport.2010.10.006

Raykov, T. (1997). Estimation of composite reliability for congeneric measures. Applied Psychological Measurement, 21, 173-184. doi:10.1177/01466216970212006

Reinartz, W.J., Haenlein, M., \& Henseler, J. (2009). An empirical comparison of the efficacy of covariance-based and variance-based SEM. International Journal of Research in Marketing, 26, 332-344. doi:10.1016/j.ijresmar.2009.08.001

Reinboth, M., Duda, J.L., \& Ntoumanis, N. (2004). Dimensions of coaching behavior, need satisfaction, and the psychological and physical welfare of young athletes. Motivation and Emotion, 28, 297-313. doi:10.1023/B:MOEM.0000040156.81924.b8

Ringle, C.M., Wende, S., \& Will, A. (2005). SmartPLS 2.0 (M3) Beta. Hamburg: http:// www.smartpls.de.

Roderick, M., \& Waddington, I. (2000). Playing hurt: Managing injuries in English professional football. International Review for the Sociology of Sport, 35, 165-180. doi:10.1177/101269000035002003

Rundmo, T., \& Hale, A.R. (2003). Managers' attitudes towards safety and accident prevention. Safety Science, 41, 557-574. doi:10.1016/S0925-7535(01)00091-1

Ryan, R.M., \& Connell, J.P. (1989). Perceived locus of causality and internalization: Examining reasons for acting in 2 domains. Journal of Personality and Social Psychology, 57, 749-761. PubMed doi:10.1037/0022-3514.57.5.749

Ryan, R.M., \& Deci, E.L. (2000). The darker and brighter sides of human existence: Basic psychological needs as a unifying concept. Psychological Inquiry, 11, 319-338. doi:10.1207/S15327965PLI1104_03

Vallerand, R.J. (2000). Deci and Ryan's self-determination theory: A view from the hierarchical model of intrinsic and extrinsic motivation. Psychological Inquiry, 11, 312-318.

Verhagen, E.A.L.M., van Stralen, M.M., \& van Mechelen, W. (2010). Behaviour, the key factor for sports injury prevention. Sports Medicine (Auckland, N.Z.), 40, 899-906. PubMed doi:10.2165/11536890-000000000-00000

Williams, G.C., \& Deci, E.L. (1996). Internalization of biopsychosocial values by medical students: A test of self-determination theory. Journal of Personality and Social Psychology, 70, 767-779. PubMed doi:10.1037/0022-3514.70.4.767

Williams, G.C., Grow, V.M., Freedman, Z.R., Ryan, R.M., \& Deci, E.L. (1996). Motivational predictors of weight loss and weight-loss maintenance. Journal of Personality and Social Psychology, 70, 115-126. PubMed doi:10.1037/0022-3514.70.1.115

Wu, C.Y., \& Hwang, M.T. (2000). Evaluating motivatonal deficits in individuals with mental illness: The Chinese General Causality Orientations Scale. Occupational Therapy International, 7, 57-77. doi:10.1002/oti.107

Zhao, X.S., Lynch, J.G., \& Chen, Q.M. (2010). Reconsidering Baron and Kenny: Myths and truths about mediation analysis. The Journal of Consumer Research, 37, 197-206. doi:10.1086/651257

Manuscript submitted: November 5, 2011

Revision accepted: July 23, 2012 


\section{Appendix}

\section{Appendix Table Information on the Scales}

\begin{tabular}{|c|c|c|c|c|}
\hline Variable & Questionnaire & Dimension & Example Item & Anchors \\
\hline $\begin{array}{l}\text { Autonomy } \\
\text { support from } \\
\text { coaches }\end{array}$ & $\begin{array}{l}\text { HCCQ (Williams et } \\
\text { al., 1996) }\end{array}$ & $\begin{array}{l}\text { Perceived Auton- } \\
\text { omy support }\end{array}$ & $\begin{array}{l}\text { My coach listens to } \\
\text { how I would like to do } \\
\text { things }\end{array}$ & $\begin{array}{l}1=\text { not at } \\
\text { all true, } 7= \\
\text { very true }\end{array}$ \\
\hline \multirow[t]{3}{*}{$\begin{array}{l}\text { Basic psycho- } \\
\text { logical need } \\
\text { satisfaction }\end{array}$} & $\begin{array}{l}\text { BNSSS (Ng et al., } \\
\text { 2011) }\end{array}$ & Autonomy & $\begin{array}{l}\text { In my sport, I have a } \\
\text { say in how things are } \\
\text { done }\end{array}$ & $\begin{array}{l}1=\text { not at } \\
\text { all true, } 7= \\
\text { very true }\end{array}$ \\
\hline & & Competence & I am skilled at my sport & \\
\hline & & Relatedness & $\begin{array}{l}\text { In my sport, I feel close } \\
\text { to other people }\end{array}$ & \\
\hline \multirow[t]{5}{*}{$\begin{array}{l}\text { Motivation in } \\
\text { sport }\end{array}$} & $\begin{array}{l}\text { BRSQ (Lonsdale et } \\
\text { al., 2008) }\end{array}$ & $\begin{array}{l}\text { Intrinsic motiva- } \\
\text { tion }\end{array}$ & $\begin{array}{l}\text { I participate in my sport } \\
\text { because I enjoy it }\end{array}$ & $\begin{array}{l}1=\text { not at } \\
\text { all true }, 7=\end{array}$ \\
\hline & & Integration & $\begin{array}{l}\text { I participate in my sport } \\
\text { because it's a part of } \\
\text { who I am }\end{array}$ & very true \\
\hline & & Identification & $\begin{array}{l}\text { I participate in my sport } \\
\text { because I value the ben- } \\
\text { efits of my sport }\end{array}$ & \\
\hline & & Introjection & $\begin{array}{l}\text { I participate in my sport } \\
\text { because I would feel } \\
\text { guilty if I quit }\end{array}$ & \\
\hline & & $\begin{array}{l}\text { External motiva- } \\
\text { tion }\end{array}$ & $\begin{array}{l}\text { I participate in my sport } \\
\text { because I feel pressure } \\
\text { from other people to } \\
\text { play }\end{array}$ & \\
\hline \multirow[t]{2}{*}{$\begin{array}{l}\text { Motivation for } \\
\text { sport injury pre- } \\
\text { vention }\end{array}$} & $\begin{array}{l}\text { TSRQ (Chan \& } \\
\text { Hagger, 2012b) }\end{array}$ & $\begin{array}{l}\text { Autonomous } \\
\text { motivation }\end{array}$ & $\begin{array}{l}\text { I want to prevent or } \\
\text { avoid sport injury } \\
\text { because it is an impor- } \\
\text { tant choice I really want } \\
\text { to make }\end{array}$ & $\begin{array}{l}1=\text { not at } \\
\text { all true, } 7= \\
\text { very true }\end{array}$ \\
\hline & & $\begin{array}{l}\text { Controlled moti- } \\
\text { vation }\end{array}$ & $\begin{array}{l}\text { I want to prevent or } \\
\text { avoid sport injury } \\
\text { because I would feel } \\
\text { guilty or ashamed of } \\
\text { myself if did not }\end{array}$ & \\
\hline
\end{tabular}


Appendix Table, continued

\begin{tabular}{|c|c|c|c|c|}
\hline Variable & Questionnaire & Dimension & Example Item & Anchors \\
\hline \multirow[t]{2}{*}{ Adherence } & \multirow[t]{2}{*}{$\begin{array}{l}\text { Adapted from the } \\
\text { Self-Reported } \\
\text { Injury Prevention } \\
\text { Adherence Scale } \\
\text { (Chan \& Hagger, } \\
\text { 2012a) }\end{array}$} & Frequency & $\begin{array}{l}\text { How often do you } \\
\text { work on improving } \\
\text { your physical/ mental } \\
\text { conditions to avoid } \\
\text { injuries (e.g., warm-up, } \\
\text { stretching, physical } \\
\text { conditioning, resting } \\
\text { adequately)? }\end{array}$ & $\begin{array}{l}1=\text { never } \\
7=\text { very } \\
\text { often }\end{array}$ \\
\hline & & Effort & $\begin{array}{l}\text { How much effort do } \\
\text { you put on avoiding } \\
\text { reinjury for your old } \\
\text { injuries (e.g., use of } \\
\text { ice, banding, taking } \\
\text { supplements)? }\end{array}$ & $\begin{array}{l}1= \\
\text { minimum } \\
\text { effort, } 7= \\
\text { maximum } \\
\text { effort }\end{array}$ \\
\hline \multirow[t]{6}{*}{ Injury beliefs } & \multirow{6}{*}{$\begin{array}{l}\text { Adapted from } \\
\text { MSAQ (Rundmo \& } \\
\text { Hale, 2003) }\end{array}$} & $\begin{array}{l}\text { Safety } \\
\text { commitment }\end{array}$ & $\begin{array}{l}\text { I am concerned about } \\
\text { safety in sport }\end{array}$ & \multirow{6}{*}{$\begin{array}{l}1= \\
\text { strongly } \\
\text { disagree, } 7 \\
=\text { strongly } \\
\text { agree }\end{array}$} \\
\hline & & Injury priority & $\begin{array}{l}\text { There is nothing more } \\
\text { important than safety } \\
\text { in sport }\end{array}$ & \\
\hline & & $\begin{array}{l}\text { Fatalism } \\
\text { concerning injury } \\
\text { prevention }\end{array}$ & $\begin{array}{l}\text { Sport injuries just } \\
\text { happen, there is little } \\
\text { one can do to avoid } \\
\text { them }\end{array}$ & \\
\hline & & $\begin{array}{l}\text { Attitude toward } \\
\text { safety violation }\end{array}$ & $\begin{array}{l}\text { Sometimes it is } \\
\text { necessary to ignore } \\
\text { safety regulations to } \\
\text { perform better in sport }\end{array}$ & \\
\hline & & $\begin{array}{l}\text { Barriers to safety } \\
\text { communication }\end{array}$ & $\begin{array}{l}\text { Talking to the others } \\
\text { (e.g., athletes, coaches, } \\
\text { and medical staff) } \\
\text { about injury prevention } \\
\text { is difficult. }\end{array}$ & \\
\hline & & Injury worry & $\begin{array}{l}\text { I am a bit afraid when I } \\
\text { think about sport injury }\end{array}$ & \\
\hline \multirow[t]{3}{*}{$\begin{array}{l}\text { General } \\
\text { causality } \\
\text { orientation }\end{array}$} & \multirow[t]{3}{*}{$\begin{array}{l}\text { GCOS (Deci \& } \\
\text { Ryan, 1985a) }\end{array}$} & & $\begin{array}{l}\text { Instruction: You } \\
\text { are embarking on a } \\
\text { new career. The most } \\
\text { important consideration } \\
\text { is likely to be: }\end{array}$ & \\
\hline & & $\begin{array}{l}\text { Autonomy } \\
\text { orientation }\end{array}$ & $\begin{array}{l}\text { How interested you are } \\
\text { in that kind of work }\end{array}$ & \multirow{2}{*}{$\begin{array}{l}1=\text { very } \\
\text { unlikely, } \\
7=\text { very } \\
\text { likely }\end{array}$} \\
\hline & & $\begin{array}{l}\text { Controlled } \\
\text { orientation }\end{array}$ & $\begin{array}{l}\text { Whether there are } \\
\text { good possibilities for } \\
\text { advancement }\end{array}$ & \\
\hline
\end{tabular}

